Won et al. Journal of Open Innovation: Technology, Market, and Complexity (2015) 1:22

DOI 10.1186/s40852-015-0023-7
( $)$ Journal of Open Innovation: Technology, Market, and Complexity

a SpringerOpen Journal

Open Access

\title{
Complex adaptive systems approach to sewol ferry disaster in Korea
}

\author{
DongKyu Won, SunHee Yoo, HyungSun Yoo and JongYeon Lim
}

\author{
* Correspondence: \\ jylim@kisti.re.kr \\ KISTI (Korea Institute of Science and \\ Technology Information), Daejeon, \\ Korea
}

\begin{abstract}
This paper aims to introduce the concept and characteristics of natech disaster (natural hazards triggered technological disaster) and to explore the policy issues in complex disaster management in Korea. This research examines the issues of natech complex disaster through analysis of Sewol ferry disaster. Various variables of developing the risk communication are derived using bow-tie model, and the detailed causes are derived using ABM (Agent-based model). Therefore, this study is to apply the catastrophe based approach for improving effective holistic approaches to disaster and to investigate the changing factor analysis of the risk communication with dynamic characteristics using the model of complex adaptive systems. Based on the results of analyzes, this research concludes with a few policy suggestions.

First, the natech complex disaster management needs to be approached in complex adaptive perspective. Second, by psychological, social network analysis, and linking reaction after the disaster, we could cope with the physical disaster similar in the future. Thus, the concepts of hazard and vulnerability cannot be defined independently of one another. Third, the perception of vulnerability as a "psychological event" implies that disaster has a point of beginning and an end. Therefore, determines vulnerability management actions as prevention or mitigation (before), emergency response (during) and long-term rehabilitation and development (after), which together form part of the vulnerability management cycle.

In conclusion, complex adaptive systems approach to the vulnerability could cause us to change our focus on preparing for the impact of events, and perhaps it should induce us to widen our horizon concerning the dynamics and implications of the natech disaster.
\end{abstract}

Keywords: Sewol ferry disaster, Natech disaster, Disaster management, Complex adaptive systems, Bow-tie model, Social network model, ABM (Agent-based model)

\section{Policy issues in natech disaster management}

This thesis aims to introduce the concept and characteristics of natech disaster ${ }^{1}$ (natural hazards triggered technological disaster) and to explore the policy issues in complex disaster management in Korea (Vetere et al. 2004). Natech disaster (or risk) has been studied in European countries and America since late 1990s. As the disastrous accident in Fukushima nuclear power plant hit by Tsunami in early 2011 proved the unmanageable size and impact of the complex disaster, the issues in Natech disaster has drawn attention from all over the world. There is growing evidence that natural disasters can trigger multiple and simultaneous chemical accidents, etc.

(c) 2015 Won et al. Open Access This article is distributed under the terms of the Creative Commons Attribution 4.0 International License (http://creativecommons.org/licenses/by/4.0/), which permits unrestricted use, distribution, and reproduction in any medium provided you give appropriate credit to the original author(s) and the source, provide a link to the Creative Commons license, and indicate if changes were made. 
The sinking of the Sewol ferry occurred on the morning of 16 April 2014 en route from Inchon to Jujus. The Japanese-built Korean ferry capsized while carrying 476 people, mostly secondary school students. The sinking of Sewol ferry has resulted in widespread social and political reaction within Korea. Many criticize the actions of the captain and most of the crew of the ferry. More criticize the ferry operator and the regulators who oversaw its operations. Additional criticism has been directed at the Korean government and media for its disaster response and attempts to downplay government culpability. This event has the characteristics of typical natech. The systematic study of the interaction between natural and technological disasters is an area that has attracted growing attention in the last decade. Awareness of natechs as an "emerging systemic risk" has grown in Europe (Cruz et al., 2004).

Generally speaking, the relentless evolution of technology provides sources of both vulnerability and its mitigation: it is a double-edged sword (Alexander, 1995). Holistic approaches to disaster (McEntire, 2001) have developed a portrait of the modern complex emergency, a phenomenon characterized by a mixture of military, social, economic, political and environmental instability aggravated by recurrent natural disasters and underpinned by regional or global political strategies.

Proponents of the idea argue that the complex emergency is the fruit of globalization, the shifting global power balance, decolonization and the world arms trade (Copat, 1981; Duffield 1996). Opponents argue that all disasters are more or less complex, and the roots of the so-called 'complex emergency' are a matter of sustainable development and political stability. However, neither group would dispute the fact that people caught up in complex emergencies evolve patterns of coping and survival, sometimes spontaneously (Kirkby et al., 1997).

Earthquakes, storms, and torrential rains are natural phenomena we refer to as "hazards" and are not considered to be disasters in and of themselves. For instance, an earthquake that occurs on a desert island does not trigger a disaster because there is no existing population or property affected. Also to a hazard, some "vulnerability" to the natural phenomenon must be present for an event to constitute a natural disaster. "Vulnerability" is defined as a condition resulting from physical, social, economic, and environmental factors or processes, which increases the susceptibility of a community to the impact of a hazard. "Exposure" is another component of disaster risk, and refers to that which is affected by natural disasters, such as people and property (Rohit, 2005).

In general, "risk" is defined as the expectation value of losses (deaths, injuries and property, etc.) that would be caused by a hazard. Disaster risk can be seen as a function of the hazard, exposure and vulnerability as follows;

$$
\text { Disaster Risk }=\{\mathrm{H}, \mathrm{V}, \mathrm{E}, \mathrm{B}, \mathrm{Rr}, \mathrm{Dr}, \ldots\}
$$

Risk is a function of hazard $(\mathrm{H})$, vulnerability $(\mathrm{V})$, exposure of vulnerable elements to the hazard (E), background levels of the hazard (B), the release rate of the hazard ( $R r)$, the dose rate of those elements or people that absorb its impact (Dr), and sundry other qualifiers (Alexander, 2000:15).

And, the classic model of causality for disaster is 


$$
\text { Hazard -- > Vulnerability }-->\text { Disaster }
$$

in which hazard acts upon vulnerability to produce disaster. However, this model ignores the role of human action in modifying exposure to the hazard, if not the hazard itself, and the appreciation of the social, economic, cultural and strategic constraints that drive vulnerability up (Hewitt, 1983).

Growing exposure and delays in reducing vulnerabilities result in an increased number of natural disasters and greater levels of loss. Natech disaster requires a new approach to disaster management, because of its cascading effects on interdependent systems. The field of natural disaster management and that of technological disaster management, separated in research and policy process, need to integrate their expertise working within a unified disaster management system.

The four fundamental dimensions of disaster are magnitude (of the causal phenomena), intensity (of the effects of these phenomena), time (duration and frequency) and space (territorial extent and geographical variations in intensity). As most disasters are recurrent, the pattern of magnitudes and intensities distributed in space, time and social psychology is cumulative (Alexander, 1995). A traditional approach to disaster is to develop for natural science based approach, largely refers to widespread hazardous phenomenon in environmental conditions (Bell, 1999). This is the classic model of causality, in which hazard acts upon vulnerability to produce disaster, ignores the role of human action in modifying exposure to the hazard, if not the hazard itself (Hewitt, 1983).

The engineering based approach, as a form of perceived betrayal of society by its leaders, planners and providers, concentrates on major technological system failures (Horlick-Jones, 1995). But this has the lack of appreciation of the social, economic, cultural and strategic constraints that drive vulnerability up rather than down and secondly the common lack of consideration of the wide variance in human impacts associated with engineering failures (Zebrowski, 1997).

The social science based approach has given much attention to the radical, if transient, mutation of organizations, peer groups, family behavior and so on during periods of crisis (Drabek, 1986). However, this tends to be unclear about the physical and technological underpinnings of events. The human ecology approach has the emphasis on the adaptation of people and communities to natural environmental extremes (Burton et al., 1993; Oliver-Smith, 1998). This has been very effective in influencing hazard management policy towards the adoption of a wider range of non-structural solutions to the disaster problem, but many of the characterizations of culture and its role in perceiving hazards have been simple and mechanistic (Palm, 1998). Catastrophe based approach refers to the hysteresis and bifurcation in the trajectories of differentially-derived variables through dimensional spaces (Thom, 1975) can be applied to direct or indirect causal relationships in real physical environments, and in many cases only be analogy (Kennedy, 1980). But this has the common lack of consideration of the wide variance in external impacts associated with engineering failures (Zebrowski, 1997).

We will be increasingly faced with unpredictable changes causing disruption to everybody, and these unexpected changes accelerated by various fields of open innovation in society. It was shown that how understanding of and action, including engineering, human activity, policy networks, to moderate climate changes is being undertaken in the world's leading green economy (Cook 2015). And Open innovation is beginning to 
expand the research area as a macroscopic economic system, national R\&D system, individual CEO's characteristics and business model (Yun, 2015; Patra and Krishna 2015; Kim, 2015; Han, 2015), from the important solution to product and process development for the competitiveness(Chesbrough, 2003).

A new trend is beginning to develop for holistic approaches to disaster (McEntire, 2001). It stems from the realization that human well-being depends, not only on geophysical forecasting and engineering structural mitigation, but also on external factors of social and cultural cause (Oliver-Smith, 1986; Alexander, 2000).

This research examines the issues of natech complex disaster through analysis of Sewol ferry disaster. Various variables of developing the risk communication are derived using bow-tie model, and the detailed causes are derived using ABM (Agent -Based Model) (Wilensky, 1999). Therefore, this study is to apply the catastrophe based approach for improving effective holistic approaches to disaster and to investigate the changing factor analysis of the risk communication with dynamic characteristics using the model of complex adaptive systems.

\section{Research models}

\section{Social network analysis}

The disaster has several forms of significance for human communities. First of all, it is a source of death, injury, destruction, damage, disruption, etc.. Ideas on what is a significant level of these vary considerably, often in relation to mass media 'constructions', or choice of elements to emphasize, of what is significant (Goltz, 1984; Ploughman, 1995). Secondly, disaster is a marker point in history and a milestone in the lives of survivors (Lifton, 1980). Thirdly, it is an indicator of future catastrophe potential.

To investigate potential interactions between disaster signals (factors), network analysis of significant word co-occurrence patterns may help to decipher the structure of complex disaster system across psychological or temporal gradients. The current disaster management policies are analyzed based on the literature, SNA (Social Network Analysis) and ABM which are conducted to verify the issues and possible solutions in complex disaster management. This study has used R-package for SNA that provides a simple way to analyze large volumes of unlabeled text. Network analysis tools and network thinking ${ }^{2}$ (Proulx et al., 2005) have been widely used by social scientists, and computer scientists to explore interactions between entities, widely applied to exploring co-occurrence patterns between factors in complex communities or systems. Co-occurrence patterns are readily revealed, including general non-random association, common life history strategies at unexpected relationships between community or system factors.

In general, we have demonstrated the potential of exploring inter-factor correlations to gain a more integrated understanding of complex disaster structure. This analysis presents a social network analysis based on co-occurrence patterns with $\mathrm{R}$ using package "igraph". Our text data consists of the title of newspaper editorial of the KPF (Korea Press Foundation) database (http://www.kinds.or.kr) of 25 participating newspapers from April 16th, 2014 to May 28th, 2014. We were removing numbers, stemming words, and weighing a term-document matrix by term frequency. After that, it was transformed into a term-term adjacency matrix, 
based on which a graph was built. Then we plotted the graph to show the relationship between frequent terms. In the term-term adjacency matrix, the rows and columns represent terms, and every entry is the number of co-occurrences of two terms.

For time series clustering with $\mathrm{R}$, the first step is to work out an appropriate distance or similarity metric, and then, at the second step, use existing clustering techniques, such as k-means, hierarchical clustering, density-based clustering and subspace clustering, to find clustering structures (see Appendix).

The analysis results have shown that the perception of disaster is an "events", which are inherently linked to our cognition levels. That implies that disaster has a point of a beginning and an end. Therefore, we categorize disaster situations regarding the event in focus; before, during and after disasters. And this can provide important clues about new emerging network patterns so that the decision makers can predict the coming events and react in near real time. The change of clustering structure can be relating to the emerging interesting patterns. Stream event clustering is especially important to the psychological time-critical areas such as disaster monitoring, anti-terrorism, and network intrusion detection. The change of critical clustering structure in event streams involves three forms: new emerging clusters, disappearing clusters that is caused by the convergence of growing clusters, and drifting cluster centers that is we can precisely monitor the change of clustering structure in the categorical event stream (see Fig. 1). The working mechanism can be described as follows.

1. The records from the data stream are inserted into the hierarchical clustering tree sequentially.

2. After a time interval, the change of critical clustering structure in event streams involves three forms: new emerging clusters, disappearing clusters that is caused by the convergence of growing clusters, and drifting cluster.

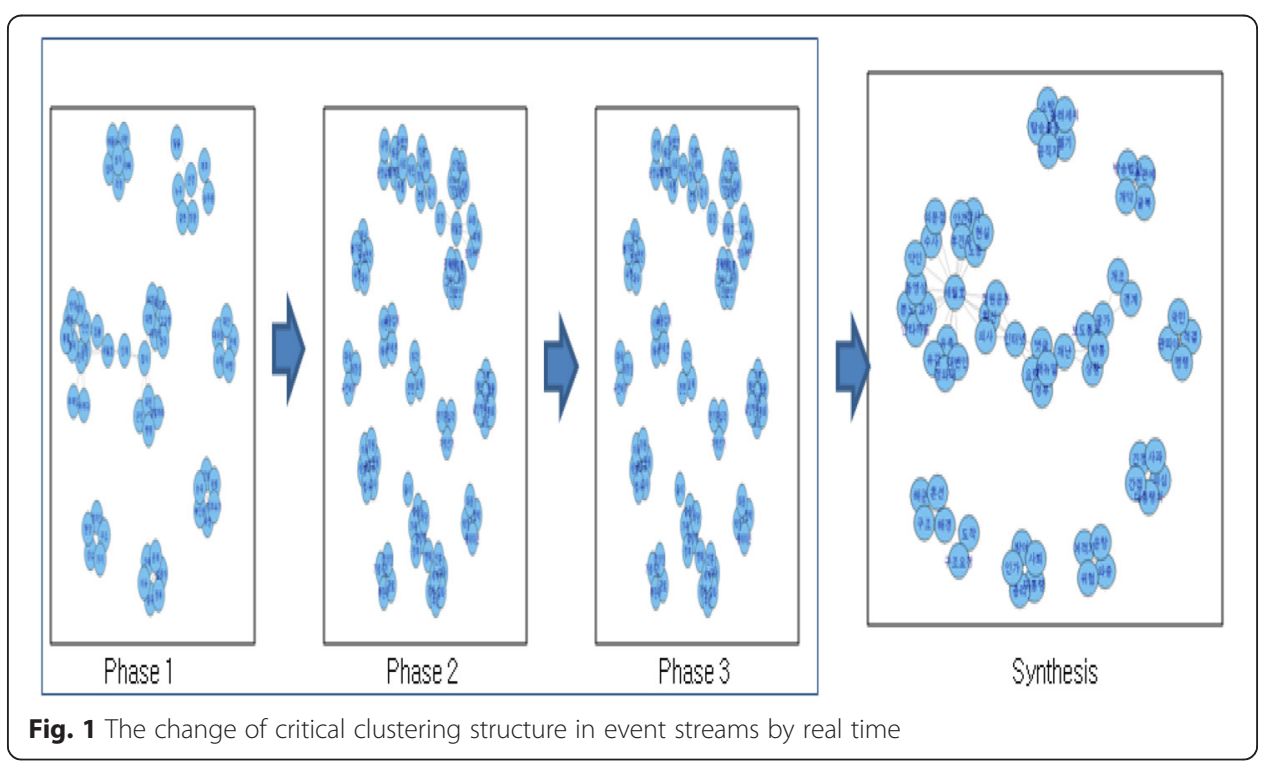


In data mining, hierarchical clustering (also called hierarchical cluster analysis) is a method of cluster analysis which seeks to build a hierarchy of clusters. The results of hierarchical clustering have presented in a dendrogram. The synthetic dataset has a two-layered clustering structure (see Fig. 2) with 30 attributes and the hierarchical clustering dendrogram would be such as below:

\section{Structure of Bow-tie model}

Bow-tie model is one of many barrier risk models available to assist the identification and management of risk, and it is this particular model we have found (and are still finding) useful (Markowski and Kotynia 2011). The Bow-tie elements that help in identifying the safety and risk priorities can also be applied. Bow-tie is a visual tool that effectively depicts risk providing an opportunity to identify and assess the key safety barriers either in place or lacking between a safety event and an unsafe outcome.

A network with bow-tie structure consists of six parts: giant strong component (GSC), substrate subset (IN), product subset (OUT), tendrils subset (Tendrils), disconnected subset (Disconnected) and tube subset (Tube). The GSC is the biggest of all strongly connected components and is much larger than all the other ones, while a strongly connected component is defined as the largest cluster of nodes within which any pair of nodes is mutually reachable from each other. IN consists of nodes that can reach the GSC but cannot be reached from it, while OUT consists of nodes that are accessible from the GSC, but do not link back to it. The "Tendrils" of the bow-tie consist of (a) the nodes reachable from "IN" that cannot reach the giant SCC, and (b) the nodes that can reach "OUT" but cannot be reached from the giant SCC. The "Disconnected" contains nodes that cannot reach the GSC, and cannot reach from it. The "Tube" travels from IN to OUT without touching the giant SCC.

By computational network analysis of the word group of psychological time series in KPF database, we discovered that the disaster structure of the Sewol ferry is organized

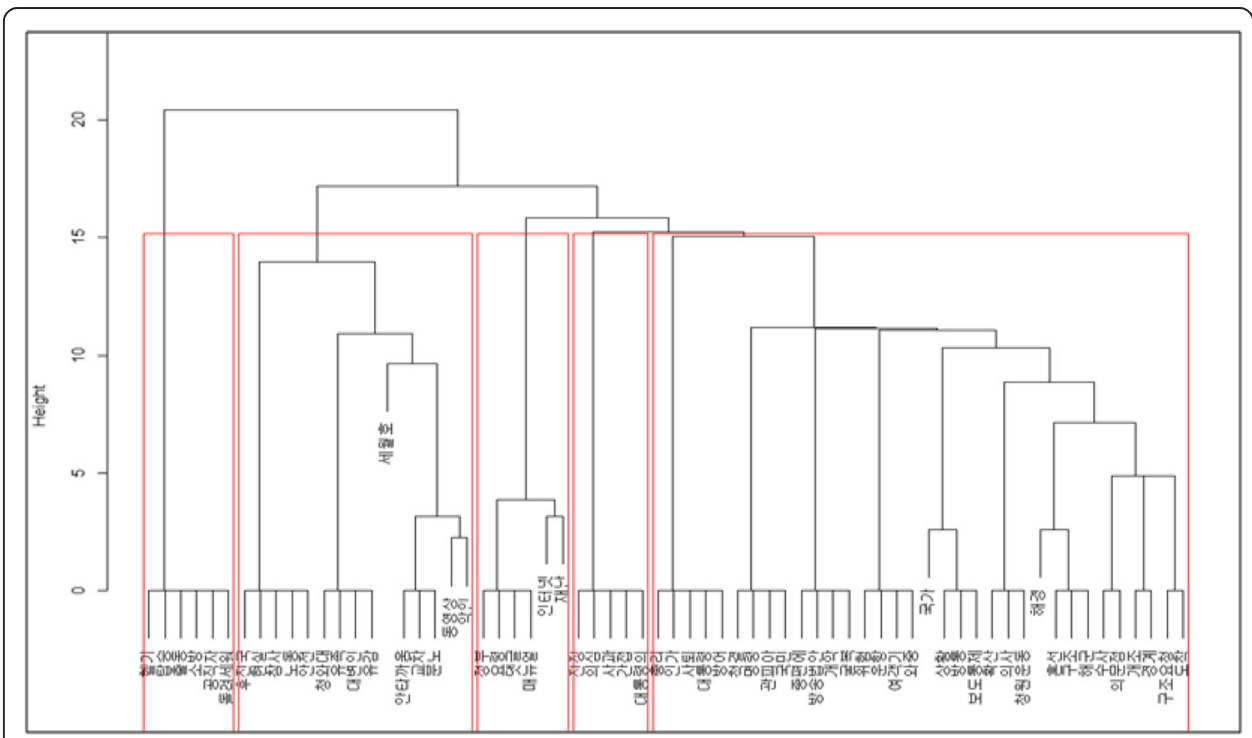

Fig. 2 Hierarchical clustering with Euclidean distance 
in the form of the bow-tie model. When reconfiguring the analysis results described above in the form of the bow-tie model is as follows (see Fig. 3): Generally, the bow-tie model is focused on the flow of the relationship between the factors. Large examining the functional significance between each group of the factors can be divided into six parts (Easley and Kleinberg 2010).

- SCC (Strongly Connected Component); it is the most strongly intertwined that component in the relationship of knowledge, it is "Exchange Zone" in that knowledge circulated.

- IN; it is a link into the SCC group, and "Source Zone" is a source of knowledge.

- OUT; it is coming links out of the SCC, it is a "Target Zone" to the the depot of knowledge.

- Tube; it is a group that is connected directly "Source Target" groups and groups without going through an intermediate point circulating.

- Tendrils; it is "Source Group" or "Target Group" to dependent manner related to that "Dependent Group".

- Disconnected Components; it is a distant group that away without exchanged all of the groups with the relationship.

A dataset suitable for clustering is a collection of points, which are objects belonging to some space. In its most general sense, a space is just a universal set of points, from which the points in the dataset are drawn. However, we should be mindful of the common case of Euclidean space, which has some important properties useful for clustering.

In particular, Euclidean space's points are vectors of real numbers. The length of the vector is the number of dimensions of the space. The components of the vector are commonly called coordinates of the represented points. We introduced the common Euclidean distance (square root of the sums of the squares of the differences between the coordinates of the points in each dimension) serves for all Euclidean spaces. It assumed that more high height of the inter-word clusters caused more cognitive events. Therefore, the height of each word group is divided into three steps for steepness vector. It assumed that the size of the steps was of a uniform size of 0.4 from 0.1 to 0.9 . And the total number of words in each group was assumed intercept values (the weight

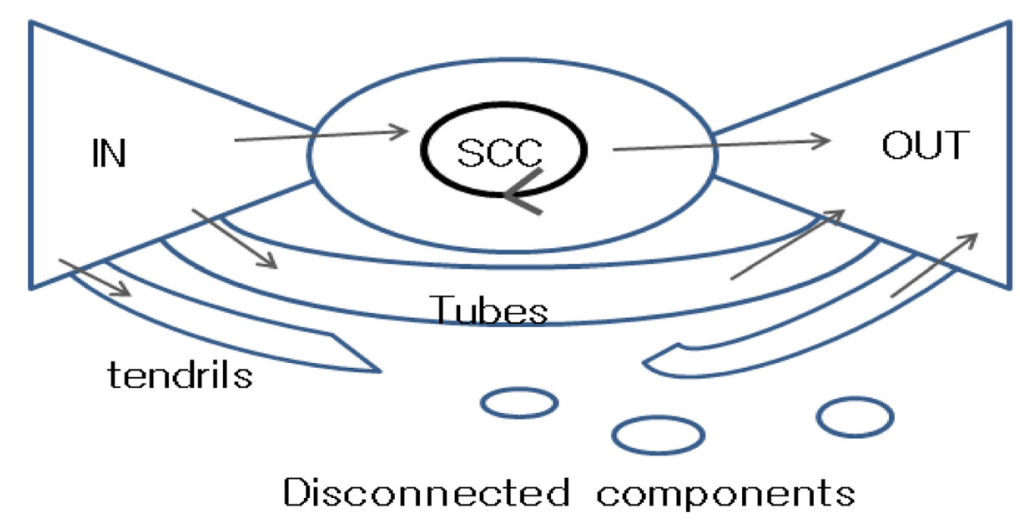

Fig. 3 Data component of the bow-tie model 
of each word is assumed to be 0.1 ). Values of the " $b_{i}$ " (intercept) of " $a_{i}$ " (steepness) of each word group based on this are as follows (see Table 1).

Figure 4 shows the "bow-tie model" from the analysis results described above. Here, 0 (Sewol ferry), 15(Internet) and 5 group (petition exercise, intention, spreading) that are intertwined most strongly, are corresponding to the "SCC". The "IN" group is the source of knowledge (Source Zone), includes the Group 1 to Group 4. Conversely, the "OUT" group includes Group 6 to Group 7. On the other hand, the cluster set included in the group 9, 10 and 11 are "Tendrils_in" that come from "IN" but cannot reach the giant SCC. Also, the cluster set included in the group 12, 13 and 14 are "Tendrils_out" that come from "OUT" but cannot reach the giant SCC.

\section{ABM (Agent-based model)}

This model is a representation of major risk factors. The nodes in this model represent the symptoms of major risk factors. According to the bow-tie model above there are sixteen factors which make direct causal relations with one another: These factors are "Sewol ferry", "sailors response system", "safety management system", "national control tower", "ship operations and management", "maritime police response system", "disaster confrontation system", "actual ship operation parts", "corresponding manual", "press control", "country remodeling", "rescue", "government accountability", "apology of the president", and "bureaucratic mafia and internet".

Table 1 Classification and characterization of clusters

\begin{tabular}{|c|c|c|c|c|}
\hline NO & Group (Cluster) & Contents & Steepness $\left(a_{i}\right)$ & intercept $\left(b_{i}\right)$ \\
\hline 0 & Sewol ferry & Sewol ferry & 0.1 & 0.1 \\
\hline 1 & sailors response system & investigation, wicked, questionable & 0.5 & 0.3 \\
\hline 2 & safety management system & $\begin{array}{l}\text { safety, disaster, labor, } \\
\text { developing countries, } \\
\text { the reality }\end{array}$ & 0.9 & 0.5 \\
\hline 3 & national control tower & $\begin{array}{l}\text { Cheong Wa Dae, the bereaved, } \\
\text { pity, spokesman }\end{array}$ & 0.9 & 0.4 \\
\hline 4 & $\begin{array}{l}\text { ship operations and } \\
\text { management }\end{array}$ & video, anger, cross, sadness & 0.5 & 0.4 \\
\hline 5 & $\begin{array}{l}\text { maritime police response } \\
\text { system }\end{array}$ & petition exercise, intention, spreading & 0.1 & 0.3 \\
\hline 6 & disaster confrontation system & comments, tips, manuals, government, disaster & 0.5 & 0.5 \\
\hline 7 & actual ship operation parts & $\begin{array}{l}\text { press control, broadcasting \& } \\
\text { telecommunications, national, } \\
\text { conditions }\end{array}$ & 0.5 & 0.6 \\
\hline 8 & corresponding manual & modifications, boundary & 0.1 & 0.2 \\
\hline 9 & press control & $\begin{array}{l}\text { navy, confusion, coast guard, } \\
\text { arrive, rescue request }\end{array}$ & 0.5 & 0.6 \\
\hline 10 & country remodeling & fire, mobilize, helicopters, boarding, stand up & 0.1 & 0.5 \\
\hline 11 & rescue & aircraft, flight, danger & 0.1 & 0.3 \\
\hline 12 & government accountability & $\begin{array}{l}\text { defense, the prime minister, } \\
\text { permission, president }\end{array}$ & 0.1 & 0.5 \\
\hline 13 & apology of the president & calm, apology, doubt, indirect, president & 0.1 & 0.5 \\
\hline 14 & bureaucratic mafia & people, bureaucratic mafia, dispel, command, & 0.1 & 0.4 \\
\hline 15 & internet & internet & 0.9 & 0.1 \\
\hline
\end{tabular}




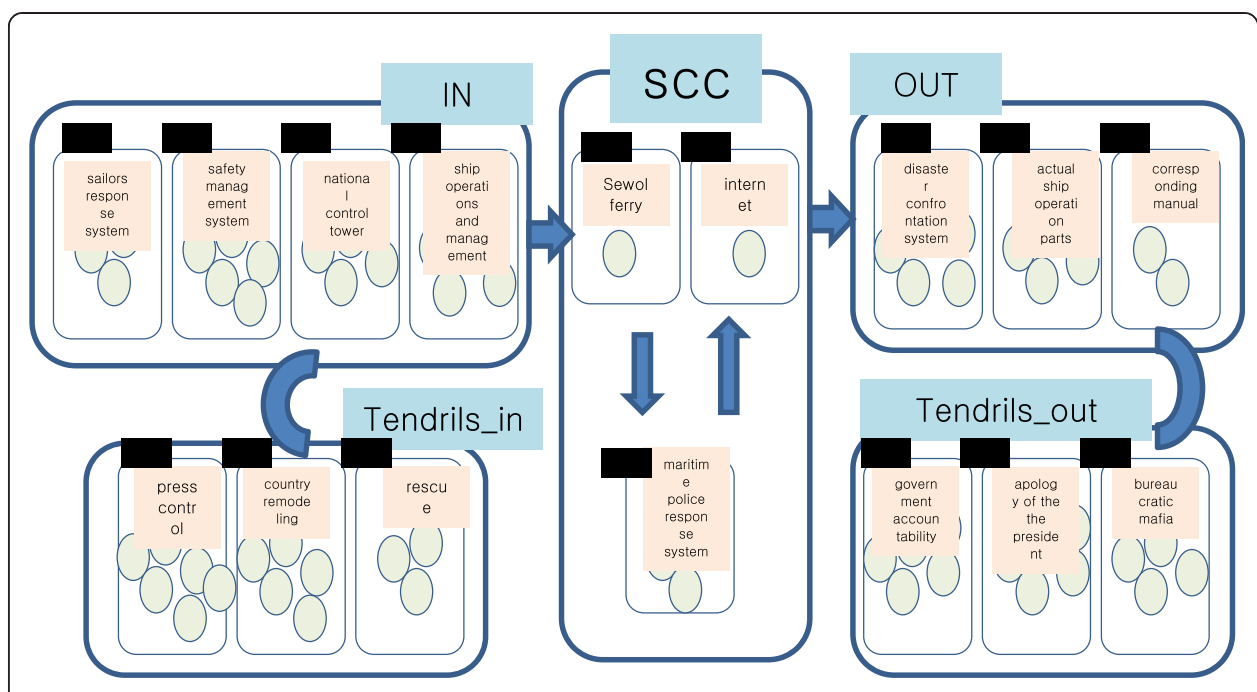

Fig. 4 Conversion to the result of the bow-tie model of clustering analysis

Therefore, these risk factors causing disruption of society were assumed to show the mutual causal direct influence with other factors and this is called the causal network perspective (Borsboom, 2008; Cramer et al. 2010; Schmittman et al. 2013; Cramer et al. 2012). For instance, if one develops a symptom of major risk factor then this increases the likelihood of developing other symptoms. Conversely, if one of the symptoms disappears, this increases the likelihood that other symptoms disappear as well. This model is made to illustrate this effect of vulnerability. Also, this model predicts that a factor that is vulnerable and develops a risk due to, for example, severe risks, will not recover automatically when the risks are solved. More is needed to trigger recovery from risks. Conversely, for the factor that is resilient to risk, mild stress cannot trigger a cascade of risks. Severe stress can lead to a full-blown risk, but when the stress subsides, the risk will subside too. This effect is also known as the hysteresis effect.

The model is based on two parameters for the whole network that can be controlled by connection strength and external activation (Van Borkulo et al. 2013). Furthermore, the stress levels can be varied per risk factor. The network architecture is based on partial correlations between risk factors. At each time step, the probability of a risk factor being developed is calculated for each risk factor. This probability depends on certain parameters as well as the total activation of its neighbors at the previous step. These parameters are regression parameters (a intercept and a steepness) for each risk factor by substituting the coefficient values which came out in the previous social network model to attribute value (" $a_{i}$ ": steepness, " $b_{i}$ ": intercept) (see Table 1 ). The parameter “ $a_{i}$ " is a risk factor-specific parameter that controls the sensitivity of the probability function. If " $\mathrm{a}_{\mathrm{i}}$ ” is high, the probability of becoming infected is larger. Parameter " $b_{i}$ " is a symptom-specific parameter for the degree of inertia of a risk factor; a risk factor with a higher threshold needs more activation to become infected than risk factors with a lower threshold. The value of the weight for the links depends on the configuration of relationships in the bow-tie model (in this case, links: 1, unlinked: 0 ).

The probability $\left(p_{i}\right)$ activated for risk factor "i" is represented as following functions. Here, " $c_{\mathrm{i}}$ " is the total amount of stress on risk factor "i". The logit of a number $p_{i}$ between 0 and 1 is given by the formula. If $\mathrm{p}_{\mathrm{i}}$ is a probability, then $p_{i} /\left(1-p_{i}\right)$ is the 
corresponding odds. The logit of the probability is the natural logarithm (with base "e") of the odds (see function (3)). Here, " $\mathrm{a}_{\mathrm{i}} \mathrm{c}_{\mathrm{i}}$ " is the total probability of becoming infected and " $\mathrm{a}_{\mathrm{i}} \mathrm{b}_{\mathrm{i}}$ " is for the total probability of inertia of a risk factor. Hence, " $\mathrm{a}_{\mathrm{i}} \mathrm{c}_{\mathrm{i}}-\mathrm{a}_{\mathrm{i}} \mathrm{b}_{\mathrm{i}}$ " is the pure probability of becoming infected. Therefore logit function is defined as follows:

$$
\operatorname{logit}\left(p_{i}\right)=\log \left(p_{i} / \mathbf{1}-p_{i}\right)=\mathbf{a}_{\mathbf{i}} \mathbf{c}_{\mathbf{i}}-\mathbf{a}_{\mathbf{i}} \mathbf{b}_{\mathbf{i}}
$$

The "logistic" function of any number is given by the inverse-logit. The logistic function is the inverse of the natural logit function and so can be used to convert the logarithm of odds into a probability; the conversion from the log-likelihood ratio of two alternatives also takes the form of a logistic curve (see function (4)). And the the inverse-logit function can be written as :

$$
\begin{aligned}
\operatorname{logit}^{-1}(p i) & =\boldsymbol{p}_{\boldsymbol{i}} \\
& =\exp \left(\mathbf{a}_{\mathbf{i}} \mathbf{c}_{\mathbf{i}}-\mathbf{a}_{\mathbf{i}} \mathbf{b}_{\mathbf{i}}\right) /\left(\exp \left(\mathbf{a}_{\mathbf{i}} \mathbf{c}_{\mathbf{i}}-\mathbf{a}_{\mathbf{i}} \mathbf{b}_{\mathbf{i}}\right)+\mathbf{1}\right) \\
& =\mathbf{1} /\left(\mathbf{1}+\exp \left(-\left(\mathbf{a}_{\mathbf{i}} \mathbf{c}_{\mathbf{i}}-\mathbf{a}_{\mathbf{i}} \mathbf{b}_{\mathbf{i}}\right)\right)\right) \\
& =\mathbf{1} /\left(\mathbf{1}+\exp \left(\boldsymbol{a}_{i} \boldsymbol{b}_{\boldsymbol{i}}-\boldsymbol{a}_{i} c_{i}\right)\right)
\end{aligned}
$$

The amount of stress consists of the individual stress level of risk factor "i", the amount of external activation and the influence of the activation of the neighbors of risk factor " $\mathrm{i}$ ". The influence of the neighbors depends on whether or not they are activated and on the strength of the connection between the activated neighbor and risk factor " $i$ ". The strength of the connections determines the degree to which the activation signal of a risk factor is sent to the other risk factors. The external activation can be seen as influences from the environment.

On the other hand, in the hysteresis plot of the agent-based model (ABM), the hysteresis effect can be demonstrated (see Fig. 5). The term "hysteresis" is derived from an ancient Greek word meaning "deficiency" or "lagging behind". Hysteresis is the time-based dependence of a system's output on current and solidarity strength between elements in the past. The dependence arises because the history affects the value of an internal state. To predict outputs, either its internal state or its history must be known. If a given input alternately increases and decreases, a typical mark of hysteresis is that the output forms a loop that may occur purely because of a dynamic lag between input and output. This effect disappears as the input changes more slowly. This effect meets the description of hysteresis given above but is often referred to as rate-dependent hysteresis to distinguish it from hysteresis with a more durable memory effect.

At a certain fixed connection strength and changing external activation, it is made visible that the shifts from depressed to healthy states and vice versa generally follow a non-linear pattern (hysteresis). The histogram represents the frequency of the number of activated risk factor per tick (the unit time) of the last 1000 ticks in the model. The network can be regarded as disordered when the total number of active risk factors is larger than 8 (above the black line in the network status plot of the model). Conversely, the network is regarded healthy when there are 8 or fewer symptoms activated (below the black line).

For the ABM analysis, first select the connection strength of the hysteresis effects of certain risk factors and activates the strength of the external shock was analyzed whether any level of the network is causing the change. To reduce the intensity of the external shock to the speed of the station at some level was analyzed whether the 


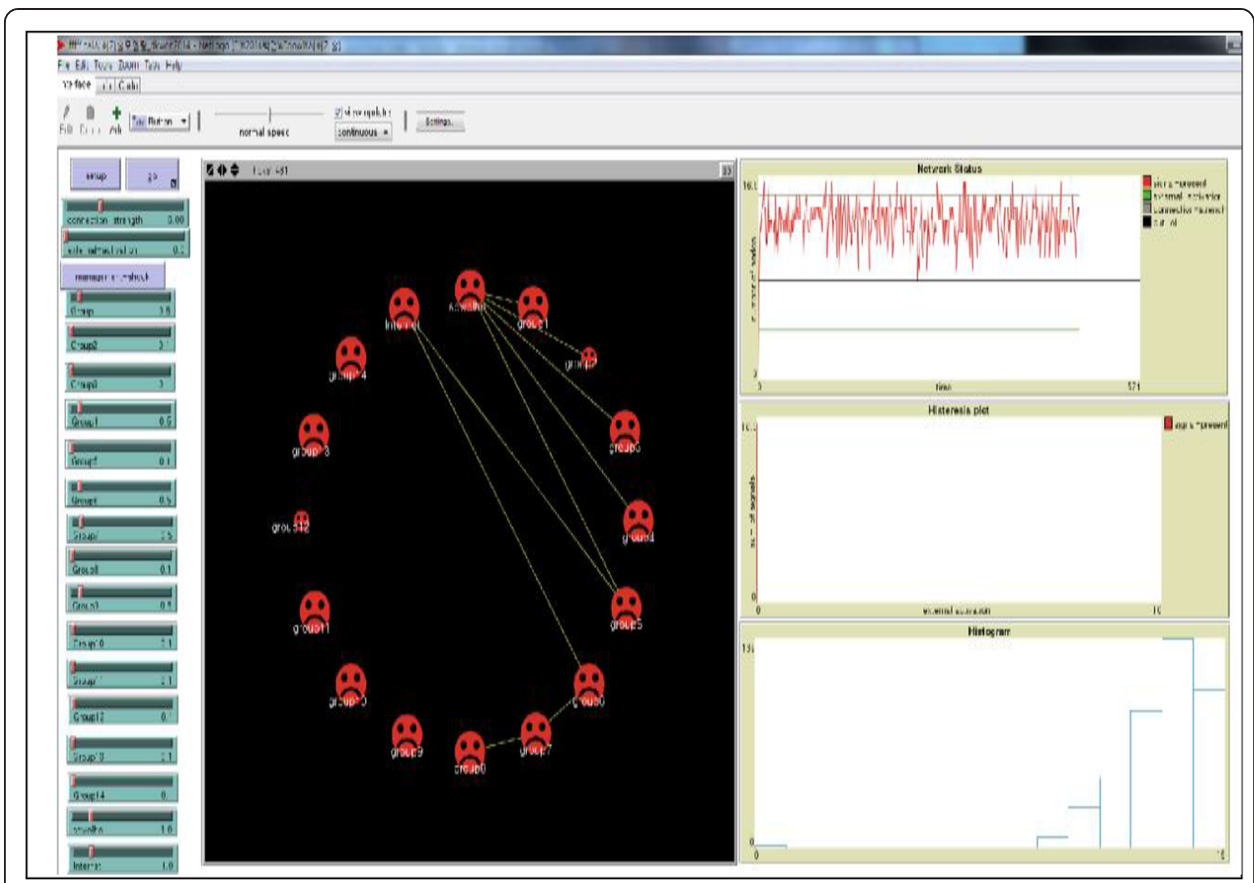

Fig. 5 Apply screen simulation models developed ABM tool NetLogo

network is switched. The following case is the hysteresis effect results under various scenarios.

\section{Hysteresis effect analysis}

For analysis of the hysteresis effect, firstly, if the level of the intensity of the external shock is activated under the connection strength of the specific risk, whether the network causes changes at which levels is analyzed. Inversely if the magnitude of an impact from the outside is reduced at the same speed, it was analyzed whether or not to switch the network to certain levels. In the following cases, it is the result of the hysteresis effect analysis under some scenarios.

$<$ Scenario $1>$ The first question we're interested in is: do the connection strength between the risks affect the frequency of disasters ? In the risk above critical threshold assuming the occurrence of a hazard (disaster) (cut-off: 8), even if increasing the connection strength between the risk factors, frequency of risk has not changed significantly. Conversely in the risk below a critical threshold, the frequency of risk has significantly changed relatively (see Fig. 6).

The results of the simulation according to the "scenario 1" mean that in the case of weak risk, the frequency of disasters could be decreasing, but the frequency variation could be difficult for large risks.

$<$ Scenario $2>$ The second question we're interested in is ; what characteristics are between the risk groups according to the impact strength from the outside? When comparing characteristics between the risk groups according to the impact strength from the outside, if the external impact is weak, high risk groups belong to IN groups (factor 3, 4, 5) in bow-tie model (see Fig. 7). Conversely, if the external if the external impact is strong, mainly risk groups in the OUT group are enabled (see Fig. 8). 


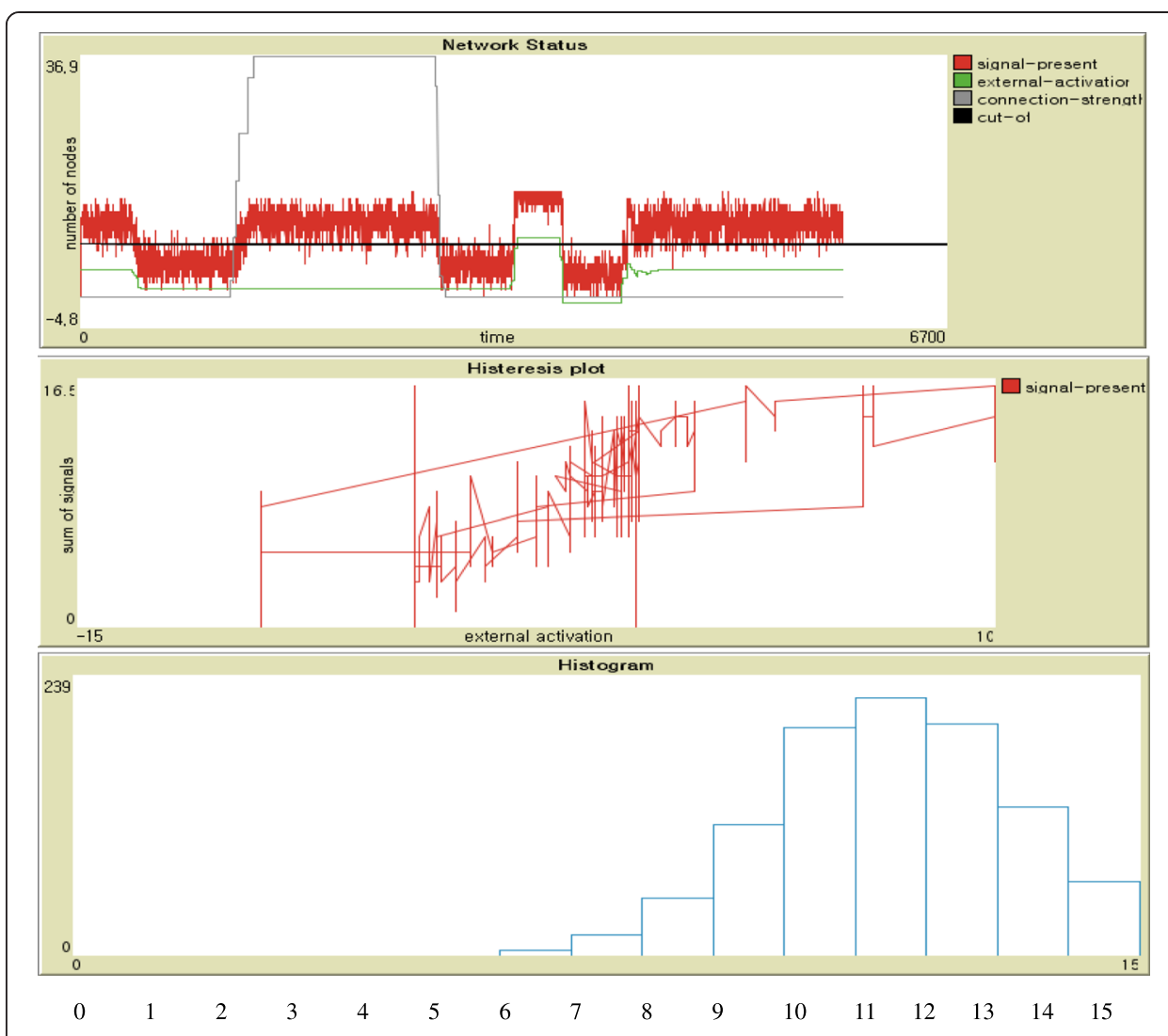

Fig. 6 Results of the hysteresis in the case of changing the connection strength between the risks

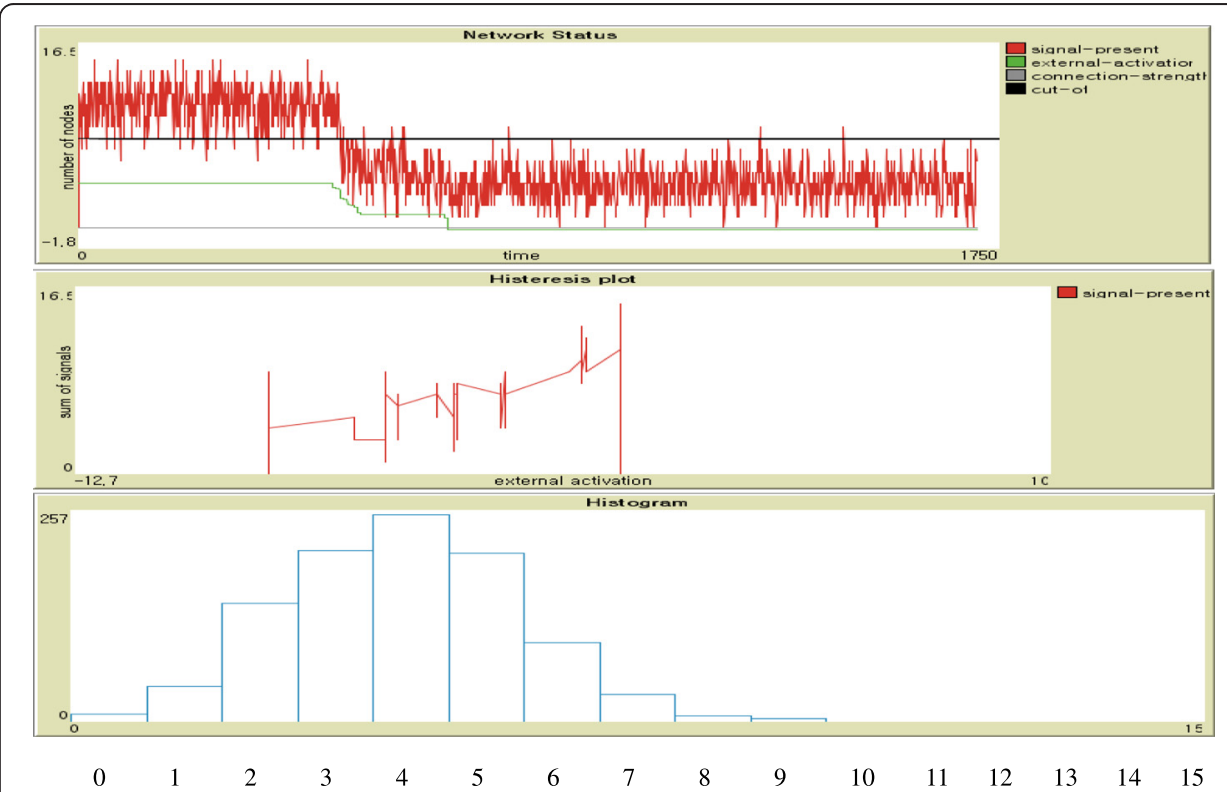

Fig. 7 Comparison results between the risk groups according to the impact strength of the external (if the external impact is weak) 


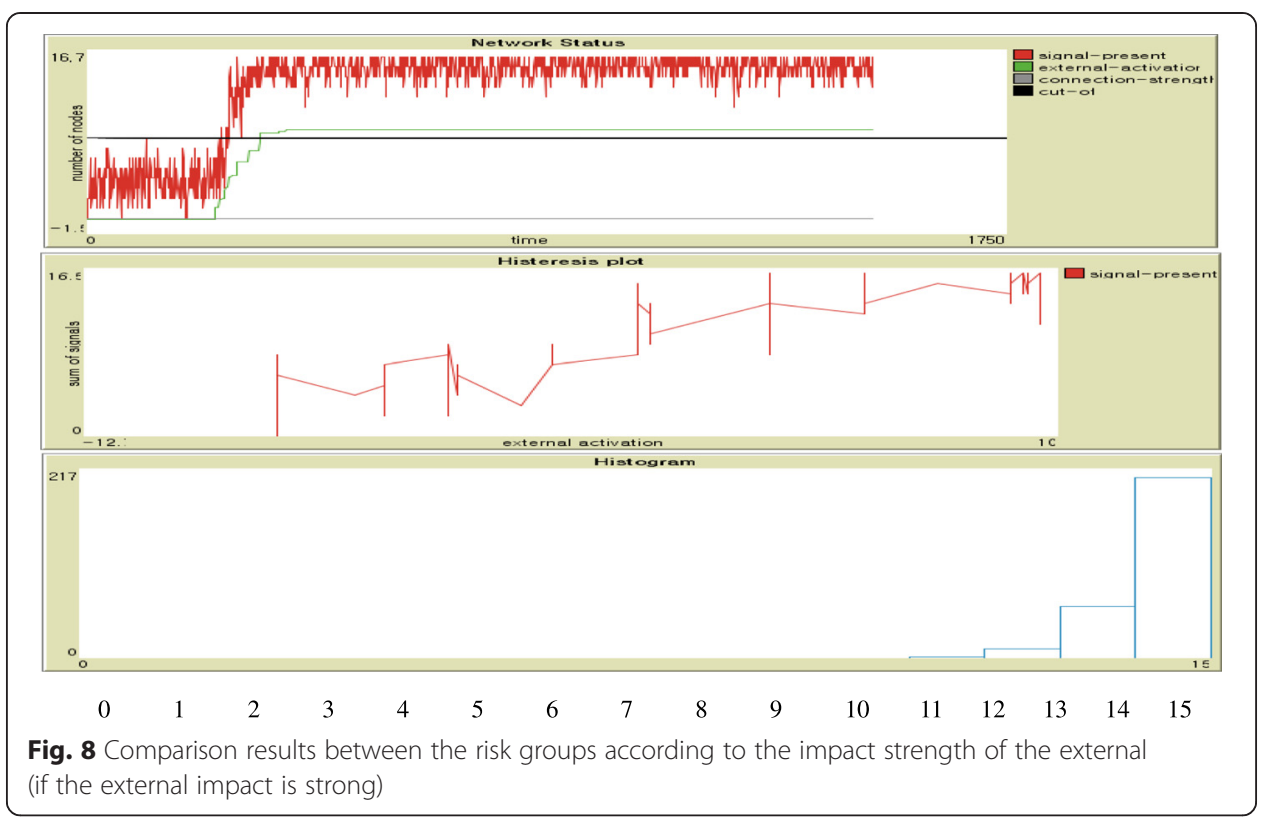

The results of the simulation according to the "scenario 2" mean that preventive measures are needed to get management of a strong external shock hazard, but constructions of ex-post infrastructure are needed to get management of the weak disaster that occurs frequently.

$<$ Scenario $3>$ The third question we're interested in is: How do the strength of the connections among the risk factors affect the frequency of risk ? In the results of hysteresis analysis in accordance with the strength of the connections among the risk factors, if the connection strength is weak, the frequency of risk factors is significantly lower in the form of mountain-shaped graph. It is usually found to be led to the 3,4 and 5 factors in the "IN group" (see Fig. 9). Conversely, if the connection strength is strong, the frequency of risk factors has changed smoothly. And it is led by the 9, 10, 11, 12, 13 and 14 factors in the "Tendrils_in" and "Tendrils_out" (see Fig. 10). The results of the simulation according to the "scenario 3 " mean that it is possible to prevent in advance the occurrence of major events through a policy of simplifying the connections between risks.

\section{Conclusion and policy recommendations}

Based on the results of analyzes, this research concludes with a few policy suggestions. First, the natech (natural-technological) complex disaster management needs to be approached in complex adaptive perspective. Four key policies applied in the bow-tie model, based on the analysis results, are as follows (see Fig. 11).

- Strengthening of forecasting for the risk itself

- Requiring cause analysis and preventive measures

- Requiring reduction measures of disaster damage through analyzing impact

- Requiring management of "tendrils group" to reduce a risk and a impact of disaster 


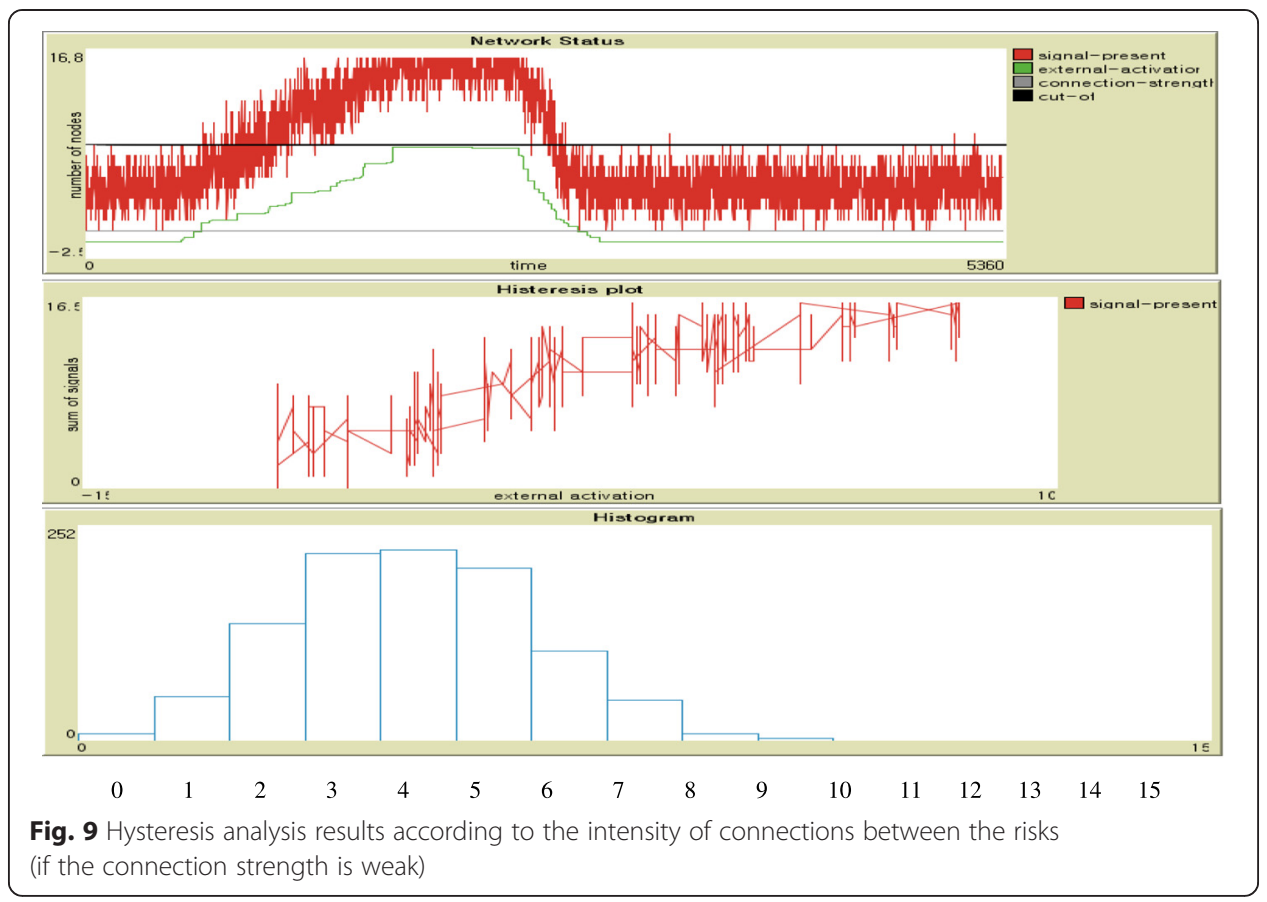

Second, disaster is the outcome of risk, which is a product of physical hazard and human or environmental vulnerability. In the risk relationship, hazards are not hazardous unless they threaten something and people or places are not vulnerable unless something threatens them. By psychological, social network analysis, and linking reaction after the disaster, we could cope with the physical disaster similar in the future. Thus, the concepts of hazard and vulnerability cannot be defined independently of one another (Alexander, 2000).

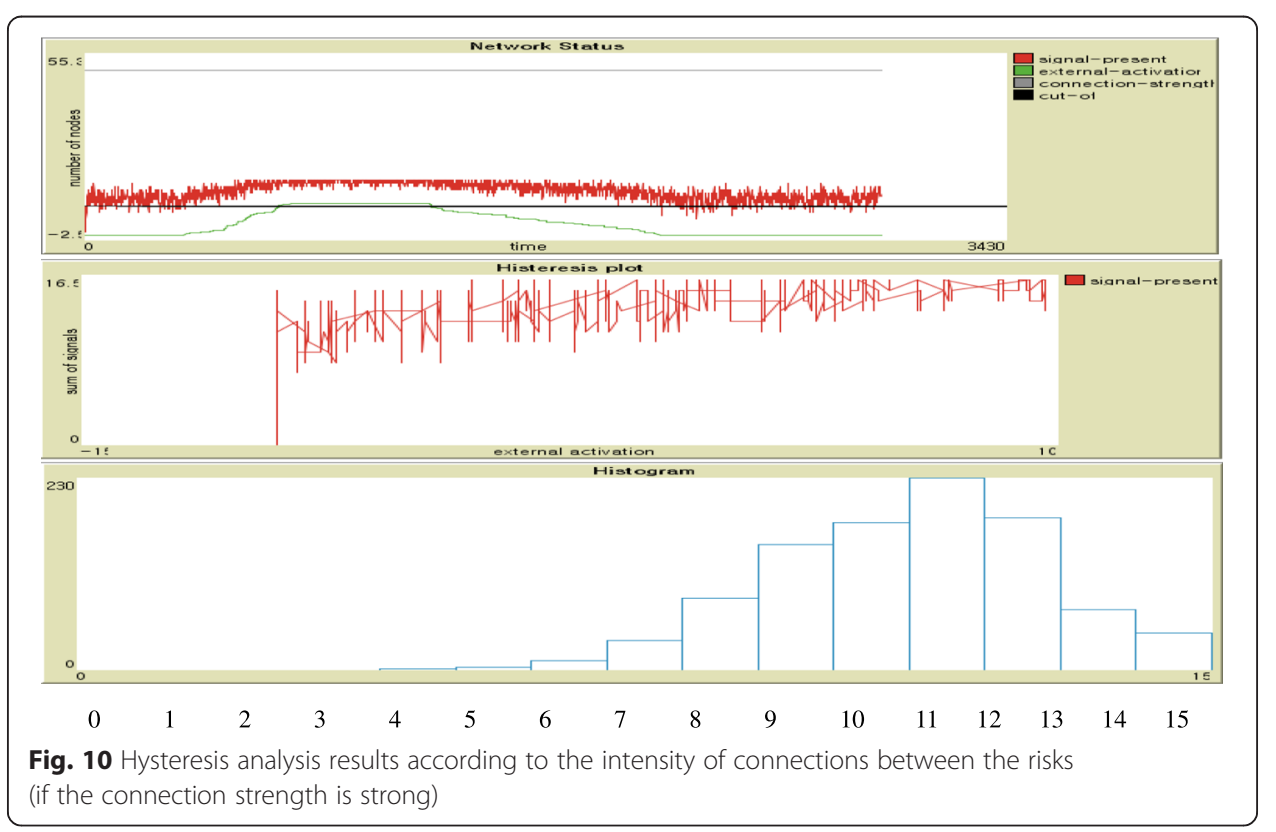




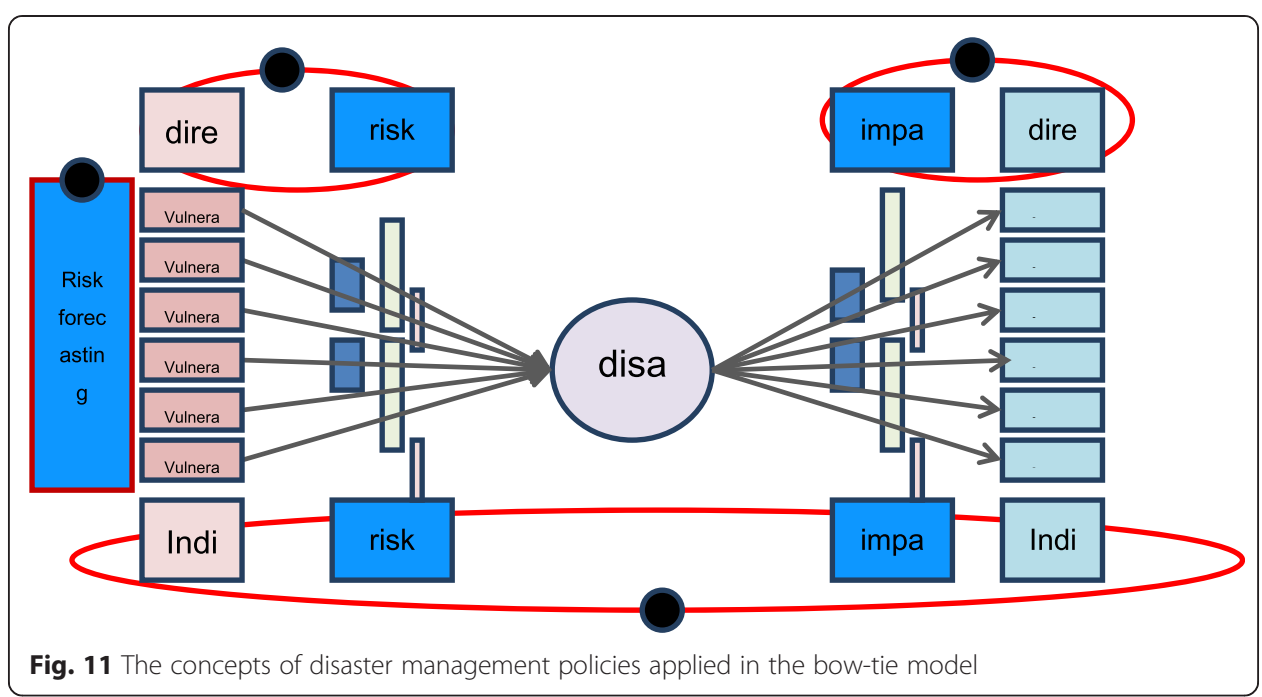

Third, the perception of vulnerability as a "psychological event" implies that disaster has a point of beginning and an end. Therefore, we categorize vulnerability situations regarding the psychological event in focus; before, during and after SCC (Strongly Connected Component) in the bow-tie model and determines vulnerability management actions as prevention or mitigation (before), emergency response (during) and longterm rehabilitation and development (after), which together form part of the vulnerability management cycle. When viewed this way, the vulnerability as well as the disaster has periods of onset, development and finally an end.

In conclusion, complex adaptive systems approach to the vulnerability could cause us to change our focus on preparing for the impact of events, and perhaps it should induce us to widen our horizon concerning the dynamics and implications of the natech disaster (see Fig. 12).

This research applied complex adaptive system with the purpose of managing risk, for adjusting the variations by the change of society, caused by the increase of the open

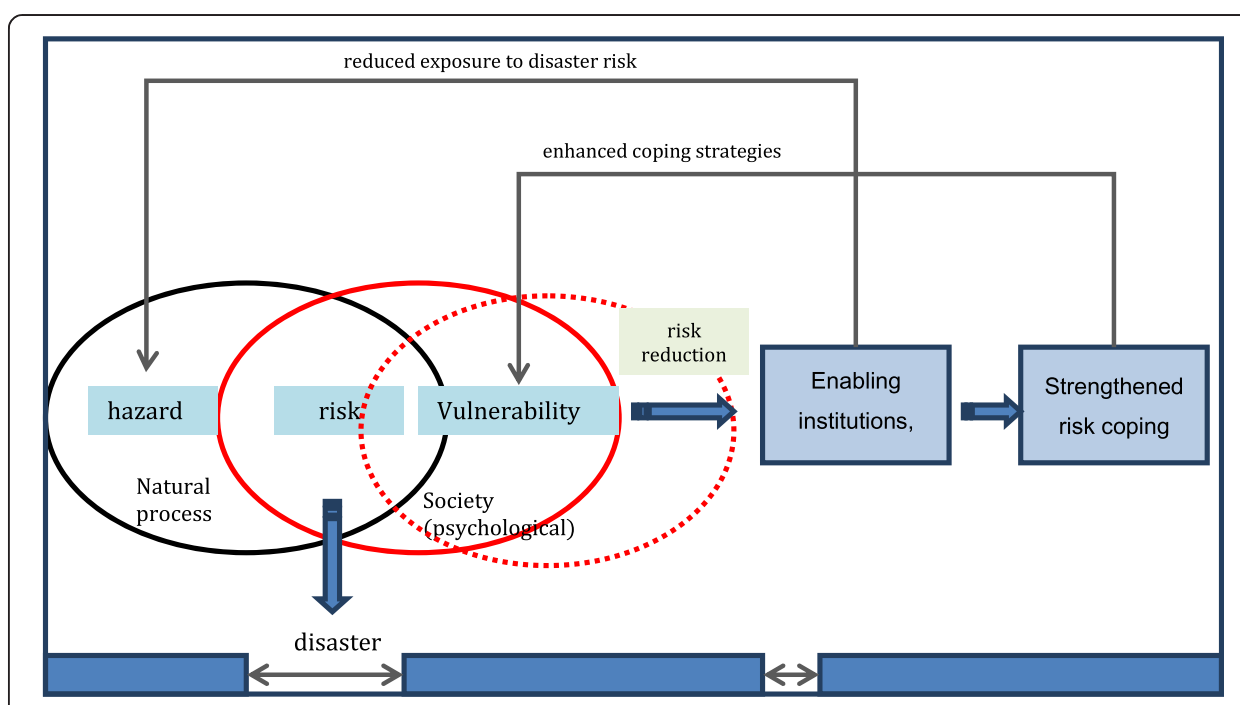

Fig. 12 Conceptual framework for sustainable vulnerability management 
innovation in every area of our life. In MERS case on 2015, we needed more holistic policy to protect crippling of nation, in the condition of the unexpected fast spread of virus, out of controlled patient's movement, public fear of proliferation, economic crisis in global society. So we hope this research could be applied to mitigate different and diverse national risk as disaster, climate change, disease, economic crisis and so on.

\section{Endnotes}

${ }^{1}$ Natural disasters can trigger technological disasters (a dynamic also called domino effect), and these concomitant events (also known as natechs) may pose tremendous risks to countries and communities.

${ }^{2} \mathrm{~A}$ network is any collection of units potentially interacting as a system.

\section{Appendix}

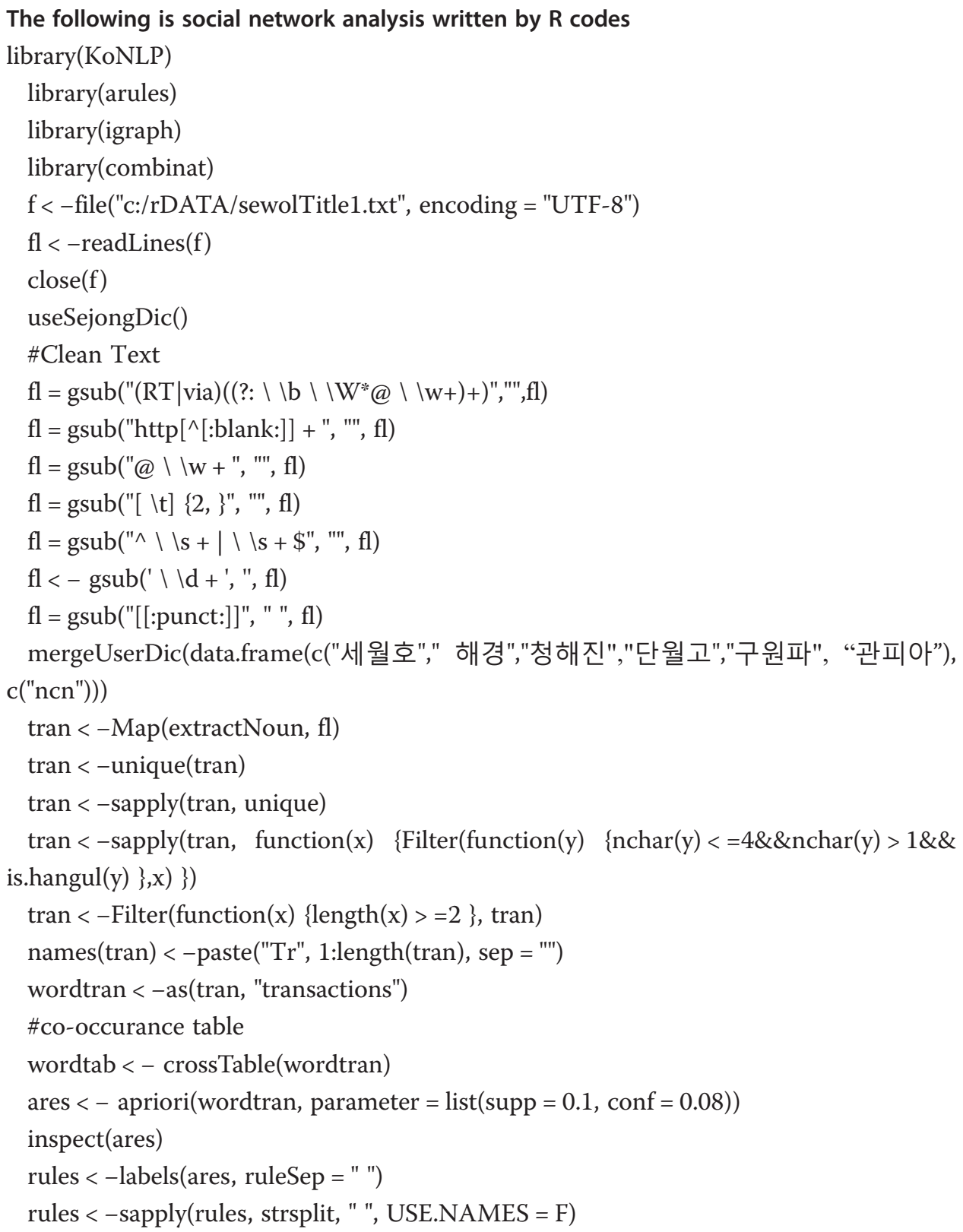




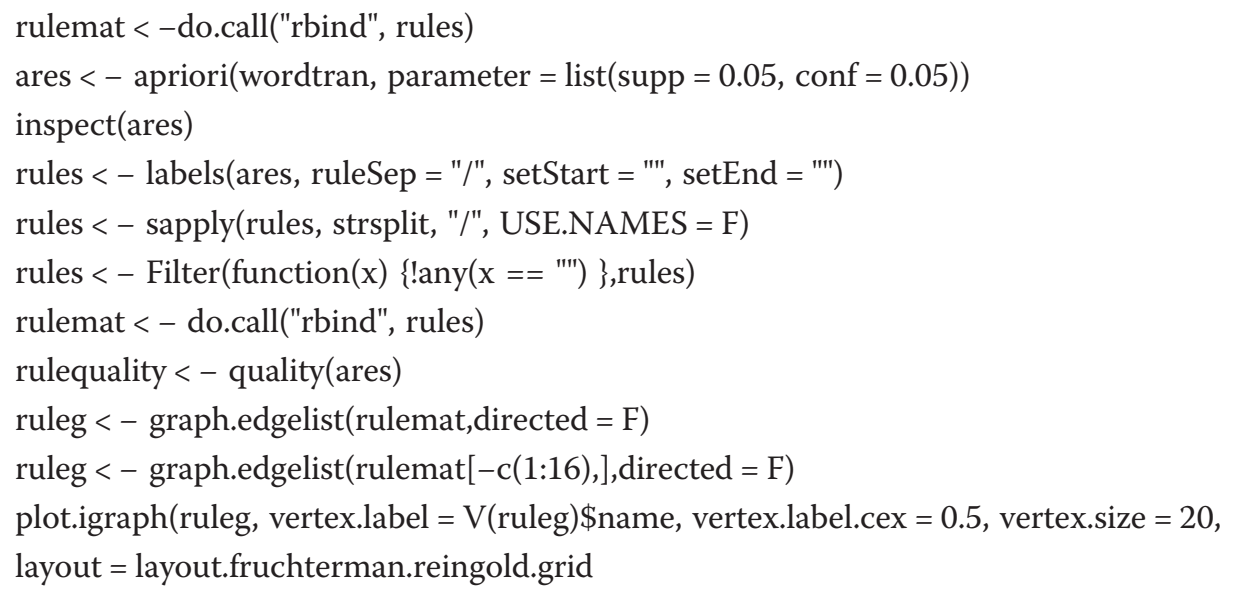

Received: 16 September 2015 Accepted: 8 December 2015

Published online: 24 December 2015

\section{References}

Alexander DE. A survey of the field of natural hazards and disaster studies. In: A. Carrara and F (editor) Geographical Information Systems in Assessing Natural Hazards. Dordrecht: Kluwer Academic Publishers; 1995. p. 1-19

Alexander DE. Confronting Catastrophe: New Perspectives on Natural Disaster. New York: Terra Publishing, Harpenden, UK, and Oxford University Press; 2000. p. 282.

Bell FG. Geological Hazards: Their Assessment, Avoidance and Mitigation. London: Routledge; 1999. 648.

Borsboom D. Psychometric perspectives on diagnostic systems. J Clin Psychol. 2008;64:1089-108.

Burton I, Kates RW, White GF. The Environment as Hazard. 2nd ed. New York: Guilford Press; 1993. p. 304.

Chesbrough HW. Open innovation: The new imperative for creating and profiting from technology. Massachusetts: Harvard Business Press; 2003.

Cook P. Green governance and green clusters: regional \& national policies for the climate change challenge of Central \& Eastern Europe. J Open Innov Technol Market Complexity. 2015;1:1.

COPAT. Bombs for Breakfast, Committee on Poverty and the Arms. London: Trade; 1981.

Cramer AOJ, Waldorp L, Van der Maas HLJ, Borsboom D. Comorbidity: A network perspective. Behav Brain Sci. 2010;33: 137-93.

Cramer AOJ, Borsboom D, Aggen SH, Kendler KS. The pathoplasticity of dysphoric episodes: differential impact of stressful life events on the patterns of depressive symptom inter-correlations. Psychol Med. 2012;42:957-65.

Cruz AM, Steinberg LJ, Arellano A, Nordvik JP, Pasano F. State of the Art in Natech Risk Management. European: Communities; 2004

Drabek TE. Human System Response to Disaster: An Inventory of Sociological Findings. New York: Springer; 1986. 509 pp.

Duffield M. The symphony of the damned: racial discourse, complex political emergencies and humanitarian aid. Disasters. 1996;20(3):173-93.

Easley D, Kleinberg J. Networks, Crowds, and Markets: Reasoning about a Highly Connected World. Cambridge: Cambridge University Press; 2010. p. 375-95.

Goltz JD. Are the news media responsible for the disaster myths? A content analysis of emergency response imagery. Int J Mass Emerg Disasters. 1984;2(3):345-68.

Han JH. Platform business Eco-model evolution: case study on Kakao Talk in Korea. J Open Innov Technol Market Complexity. 2015;1:6.

Hewitt K. The idea of calamity in a technocratic age. In: Hewitt K, editor. Interpretations of Calamity. London: Unwin-Hyman; 1983. p. 3-32

Horlick-Jones T. Modern disasters as outrage and betrayal. Int J Mass Emerg Disasters. 1995;13(3):305-15.

Kennedy BA. A naughty world, Institute of British Geographers, Transactions (New Series), 4. 1980. p. 550-8.

Kim JH. Study on CEO characteristics for management of public art performance centers. J Open Innov Technol Market Complexity. 2015;1:5.

Kirkby J, O'Keefe P, Convery I, Howell D. On the emergence of complex disasters. Disasters. 1997;21(2):177-80.

Lifton D. Best Evidence: Disguise And Deception In The Assassination of John F. Kennedy, Macmillan Publishing Company; 1980

Markowski AS, Kotynia A. "Bow-tie" model in layer of protection analysis. Process Saf Environ Prot. 2011;89:205-13.

McEntire DA. Triggering agents, vulnerabilities and disaster reduction: towards a holistic paradigm, Disaster Prevention and Management. International Journal. 2001;10(3):189-96.

Oliver-Smith A. Disaster context and causation: an overview of changing perspectives in disaster research. In: OliverSmith A, editor. Natural Disasters and Cultural Responses, Studies In Third World Societies 36. Williamsburg: College of William and Mary; 1986. p. 1-34.

Oliver-Smith A. Global challenges and the definition of disaster. In: Quarantelli EL, editor. What is a disasters: Perspectives on the question. London: Routledge; 1998. p. 177-94.

Palm R. Urban earthquake hazards: the impact of culture on perceived risk and response in the USA and Japan. Applied Geography. 1998;18(1):35-46.

Patra S, Krishna V. Globalization of R\&D and open innovation: linkages of foreign R\&D centers in India. J Open Innov Technol Market Complexity. 2015;1:7. 
Ploughman P. The American print news media 'construction' of five natural disasters. Disasters. 1995;19(4):308-26. Proulx SR, Pmislow DEL, Phillips PC. Network thinking in ecology and evolution. Trends Ecol Evol. 2005;20(6):345-53.

Rohit J. Disaster: a "reality" or construct"? Perspective from the "EAST": What is a disaster? In: Perry RW, Quarantelli EL, editors. International Research Committee on Disasters. 2005. p. 40-59.

Schmittman VD, Cramer AOJ, Waldorp LJ, Epskamp S, Kievit RA, Borsboom D. Deconstructing the construct: A network perspective on psychological phenomena. New Ideas Psychol. 2013;31:43-53.

Thom R. Structural Stability and Morphogenesis: An Outline of a General Theory of Models (trans. D.H. Fowler), Addison-Wesley, Reading, Mass. 1975.

Van Borkulo CD, Van der Maas HLJ, Borsboom D, Cramer AOJ. 2013, http://ccl.northwestern.edu/netlogo/models/ community/Nulnerability_to_Depression.

Vetere A, Cruz AM, Nordvik A, Pisano F. Analysis of Natech (Natural Hazard Triggering Technological Disasters) disaster management, European Commission Joint Research Centre (JRC). 2004: 1-198

Wilensky U. Center for Connected Learning and Computer-Based Modeling. Evanston: Northwestern University; 1999. http://ccl.northwestern.edu/netlogo/.

Yun JJ. How do we conquer the growth limits of capitalism? Schumpeterian Dynamics of Open Innovation. J Open Innov Technol Market Complexity. 2015;1:17.

Zebrowski Jr E. Perils of a Restless Planet: Scientific Perspectives on Natural Disasters. Cambridge: Cambridge University Press; 1997. 306.

\section{Submit your manuscript to a SpringerOpen ${ }^{\circ}$ journal and benefit from:}

- Convenient online submission

Rigorous peer review

- Immediate publication on acceptance

- Open access: articles freely available online

- High visibility within the field

- Retaining the copyright to your article 